\title{
Editorial
}

\section{Widening the Debate}

Social Theory \& Health (2007) 5, 1-2. doi:10.1057/palgrave.sth.8700088

On 12 October 2006, Palgrave-Macmillan hosted at their London office the first of what we are confident will prove a stimulating and successful series of annual 'Social Theory and Health' lectures. The speaker was Nikolas Rose, who interrupted his sabbatical at the London School of Economics to offer a compelling and entertaining inaugural address on the advent of molecular biopolitics, somatic ethics and the spirit of biocapital and on their ramifications for life in the 21st century. It is with pleasure that the editors reproduce his lecture in this issue.

Nikolas Rose's lecture perfectly encapsulates the 'mission' of 'Social Theory and Health', which is to bridge the gap that too often exists between the propagation of theory in the health domain and programmes of empirical research, in the process bringing together authors from a variety of different disciplinary bases. Although the backgrounds of the editors is in medical sociology, it was decided that in the spirit of the journal's mission contributions should be welcomed from across a range of disciplines bearing on matters of health and healing, a decision confirmed in consultations with members of the editorial boards. We believe this is working well, thanks of course to those colleagues, ranging over continents and foci of interest as well as over disciplines, who have submitted papers of quality and interest.

Something of the range and scope of papers can be seen in the present issue. In addition to Nikolas Rose's lecture, Heidi Chirayath examines physicians' perceptions and treatment of indigent patients in the USA, finding that physicians' attributions of agency to patients they often negatively appraise contrasts with their sense that their own actions are dictated by rules of medical practice. Anne Kerr, Sarah Cunningham-Burley and Richard Tutton focus on the ambivalence typically associated with programmes of genetic research and the social environment within which they are conducted. Examining both professional and lay discourses, they analyze this 'problematic' of ambivalence and link it with broader macro-social change. Darin Weinberg offers a critical analysis of Habermas's theories of communicative action and deliberative democracy, suggesting that they cannot, without revision, accommodate the rights of citizens with learning difficulties who 
2

may be intellectually ill-equipped for participation in the deliberative public sphere. Finally, Olaug Lian draws on personal experience as well as the literature to ask whether in a globalizing world 'place' and 'community' still have relevance for medical practice.

Since the two initial issues of 2003 both momentum and variety have been maintained; 'Social Theory and Health' is not and will not become allied to any particular theoretical stance. We have eschewed, as a matter of policy, only those submissions reporting the findings of empirical studies without theoretical elaboration or innovation. If we have erred, it has been on the side of ungrounded theory. This is reasonable enough given the lack of outlets in peer-review journals for papers with a theoretical orientation.

2008 will see the first 'special issue' devoted to a specific area or topic within the health arena. Jane Ussher and Janette Perz in Australia will be co-editing a collection of papers on 'Gender, Theory and Health'. Other special issues are under consideration, but the editors and editorial boards would appreciate input from the growing numbers of subscribers to 'Social Theory and Health', either as individuals or by virtue of their institutions; or indeed from any other interested parties! We would also encourage contributions across fields currently under-represented. There have been relatively few submissions from the critical 'fringes' of disciplines other than social theory and sociology.

Papers from those versed or working in welfare and policy studies, political science, salient branches of philosophy, health psychology, health economics, disability and development studies, for example, would be welcome, as would applications of the work of major contemporary philosophers, theorists and other thinkers to health. An invitation and plea or exhortation is extended too to those outside the 'English-speaking' world and to those not employed by institutions featuring or aiming for inclusion in the elite top $10,100,1,000$, etc.

It remains to thank those of our colleagues, who have served patiently on the editorial boards and the many others who have acted as referees and book reviewers. As all editors will testify, no journal can succeed without this type of solidarity and altruism in the academic community.

Graham Scambler, Paul Higgs and Richard Levinson

Centre for Behavioural and Social Sciences in Medicine, UCL, Emory University, USA 